\title{
Caspases in T-cell receptor-induced thymocyte apoptosis
}

\author{
Di Jiang ${ }^{1}$, Lixin Zheng ${ }^{1}$ and Michael J. Lenardo ${ }^{*, 1}$ \\ 1 Molecular Development of the Immune System Section, Laboratory of \\ Immunology, National Institute of Allergy and Infectious Diseases, National \\ Institutes of Health, Bethesda, Maryland 20892-1892, USA \\ * corresponding author: Michael J. Lenardo, Laboratory of Immunology, NIAID, \\ NIH, 10 Center Drive - MSC 1892, Building 10, Room 11D09, Bethesda, \\ Maryland, 20892-1892, USA. tel: (301)-496-6753; fax: (301)-496-0222; \\ e-mail: Lenardo@nih.gov
}

Received 27.10.98; revised 17.2.99; accepted 25.2.99

Edited by B.Osborne

\begin{abstract}
Apoptosis eliminates inappropriate or autoreactive T lymphocytes during thymic development. Intracellular mediators involved in T-cell receptor (TCR)-mediated apoptosis in developing thymocytes during negative selection are therefore of great interest. Caspases, cysteine proteases that mediate mature T-cell apoptosis, have been implicated in thymocyte cell death, but their regulation is not understood. We examined caspase activities in distinct thymocyte subpopulations that represent different stages of T-cell development. We found caspase activity in $\mathrm{CD}^{+} \mathrm{CD}^{+}$double positive (DP) thymocytes, where selection involving apoptosis occurs. Earlier and later thymocyte stages exhibited no caspase activity. Only certain caspases, such as caspase-3 and caspase-8-like proteases, but not caspase-1, are active in DP thymocytes in vivo and can be activated when DP thymocytes are induced to undergo apoptosis in vitro by TCR-crosslinking. Thus, specific caspases appear to be developmentally regulated in thymocytes.
\end{abstract}

Keywords: apoptosis; caspase; thymic selection

Abbreviations: AMC, amino-methyl-coumarin; $\mathrm{CAB}$, Convanavalin A-stimulated T-cell blasts; DD, death domain; DN, double negative thymocyte; DP, double positive thymocyte; fmk, fluoromethyl ketone; FTOC, fetal thymic organ culture; ICE, interleukin-1 $\beta$-converting enzyme; PI, propidium iodide; PS, phosphotidylserine; RAC, receptor associated caspase; SP, single positive thymocyte; TCR, T-cell receptor.

\section{Introduction}

Despite significant advances in our understanding of the apoptosis signaling pathway in mature lymphocytes, the mechanism by which apoptosis is executed in immature thymocytes is not known. In mature T-lymphocytes, the caspase family of cysteine proteases are important mediators of lymphokine withdrawal apoptosis and antigen-induced cell death. ${ }^{1}$ The prototypic members of this family are mammalian interleukin-1 $\beta$ converting enzyme (ICE) $)^{2}$ and the nematode death gene ced-3 product. $^{3}$ All members of this family cleave their substrates after an aspartic acid at the P1 position. Because of this unique feature and the requirement of cysteine in the active site of the enzyme, these proteases have been named caspases (for cysteinyl, aspartate-requiring protease). In the cytoplasm of non-apoptotic cells, caspases exist as inactive proenzymes that can be activated by cleavage after aspartic acid residues by cysteine proteases. ${ }^{4}$ This suggests that caspases may be activated by an autocatalytic mechanism and/or sequential activation by upstream proteases of the same family. Activation does not require new gene expression or new protein synthesis.

Caspases can be divided into three subfamilies according to their substrate specificities. ${ }^{5-7}$ Caspases that prefer substrates with large aromatic/hydrophobic amino acids at the P4 position, such as Tyr-Val-Ala-Asp (YVAD), form the caspase-1 subfamily that includes caspase-1, -4 and -5 . The second subfamily of caspases exhibits high cleavage activity on substrates with an aspartic acid at the P4 position such as Asp-Glu-Val-Asp (DEVD). Members of this subfamily include CED3, caspase-3 (CPP32 $\beta$, caspase-2 and caspase-7. The third subfamily consists of receptor-associated caspases (RAC) that can be recruited to the cytoplasmic domain of death receptors such as CD95 (Fas or Apo-1), through interaction with the FADD/ Mort-1 adapter molecule. Once recruited, they become activated by proteolysis and cleave substrates that contain an Ile(Leu)-Glu-X-Asp (I(L)EXD) motif. Two members of this subfamily are caspase-8 (FLICE/MACH) and caspase-10 (Mch4). Specific substrates have been used to quantitate the activity of three subfamilies respectively. ${ }^{8,9}$ Using this approach it has been suggested that members from both caspase-1 and caspase-3 subfamilies are involved in TCRinduced mature T-cell apoptosis. ${ }^{10-13}$

Since thymocytes can undergo the typical cellular changes of apoptosis following TCR stimulation, caspases may play roles in thymocyte cell death. Previous studies have suggested that caspases can be activated in thymocytes. Clayton et al. suggest that TCR engagement activates caspase activity, as measured by a caspase-3 substrate, in DP thymocytes, resulting in cell death. ${ }^{14}$ Alam et al. reported that caspase- 3 is activated during thymic selection suggesting a role for this caspase in thymic development. ${ }^{15}$ However, thymocytes in mice deficient for caspase-3 are susceptible to TCR-induced death and T-cell development appears intact. ${ }^{16,17}$ Thymocytes in caspase-1 deficient mice also develop normally, although Fas-induced apoptosis is reportedly compromised. ${ }^{17}$ Hence, how specific caspases are activated in thymocytes and developmentally regulated has not been fully elucidated. In this paper we investigate the caspases naturally active in thymocyte subpopulations and study how caspases are induced in thymocytes during apoptosis caused by TCR engagement. 


\section{Results}

\section{The presence of caspase-3-like activity in DP thymocytes}

We first examined caspase activity in various thymocyte subpopulations ex vivo. Both DEVD-MCA and YVAD-MCA served as substrates to assess the activities of the caspase-3 subfamily and caspase-1 subfamily, respectively. As a positive control, a cytosolic extract of Jurkat cells treated with $500 \mathrm{ng} / \mathrm{ml}$ of soluble anti-CD95 antibody $(\mathrm{CH} 11)$ for $6 \mathrm{~h}$ was included in the assay. The treated Jurkat cells exhibited dramatic DEVD cleavage activity by comparison with untreated cells or those treated with $\mathrm{CH} 11$ and the caspase inhibitor zVAD-fmk (Figure 1). Both $\mathrm{CD}^{+}$and $\mathrm{CD}^{+} \mathrm{SP}$ thymocytes contained negligible amounts of DEVD cleavage activity. However, DP thymocytes possessed high levels of DEVD cleavage activity (Figure 1). The presence of caspase activity only in DP thymocytes, a population that is progressing through negative and positive selection, indicates that the expression of caspases is developmentally controlled and potentially functionally important. Thus, the earlier report of apoptotic thymocytes during selection could be due to caspase activation. ${ }^{18}$ In contrast to DEVD cleavage activity, YVAD cleavage activity was undetectable in all populations examined. Efforts to uncover this activity at various time points were unsucessful. This suggests that subfamily members that share the substrate specificity of caspase- 3 but not caspase- 1 are activated in thymocytes undergoing TCR-mediated thymic selcetion. Similar results were also obtained from flow cytometrically-sorted thymocyte subpopulations (data not shown).

\section{Caspase- 3 and caspase-8/10-like proteases are activated in thymocytes induced to die by anti-CD3/anti-CD28 treatment}

To understand the functional role of certain caspases in DP thymocytes, we employed an in vitro thymocyte death assay protocol using a combination of anti-CD3 and anti-CD28 antibodies to induce cell death. ${ }^{19}$ Since fresh DP thymocytes contain high levels of DEVD cleavage activity (Figure 1 and data not shown), we cultured the freshly isolated total thymocytes for $12 \mathrm{~h}$ in vitro to allow cells that had been triggered to die in vivo to be eliminated. After culture, the protease activity of the remaining thymocytes was at background levels (Figure 1, CULTURE DP Thy). DP thymocytes were isolated by panning on anti-CD8 antibodycoated plates, and subjected to plate-bound anti-CD3 and anti-CD28 antibodies. DP thymocytes responded to TCR stimulation and underwent apoptosis within $24 \mathrm{~h}$. We found that after $3 \mathrm{~h}$ of stimulation, DEVD cleavage activity began to rise above control. At the $18 \mathrm{~h}$ time point, the enzymatic activity reached a maximum (Figure $2 \mathrm{~A}$ and $\mathrm{B}$ ). In contrast to DEVD cleavage activity, YVAD cleavage activity did not increase above control as time progressed. This result suggests that caspases specific for DEVD cleavage but not YVAD cleavage can respond to TCR engagement in thymocytes. Anti-CD3 or anti-CD28 antibody treatment alone did not activate any DEVD cleavage activity (data not shown). In these experiments we also detected a transient activation of protease activities using substrate LETD-MCA and IEADMCA that are specific for caspase-8 and caspase-10, respectively. These activities rose and fell between 2 to $6 \mathrm{~h}$

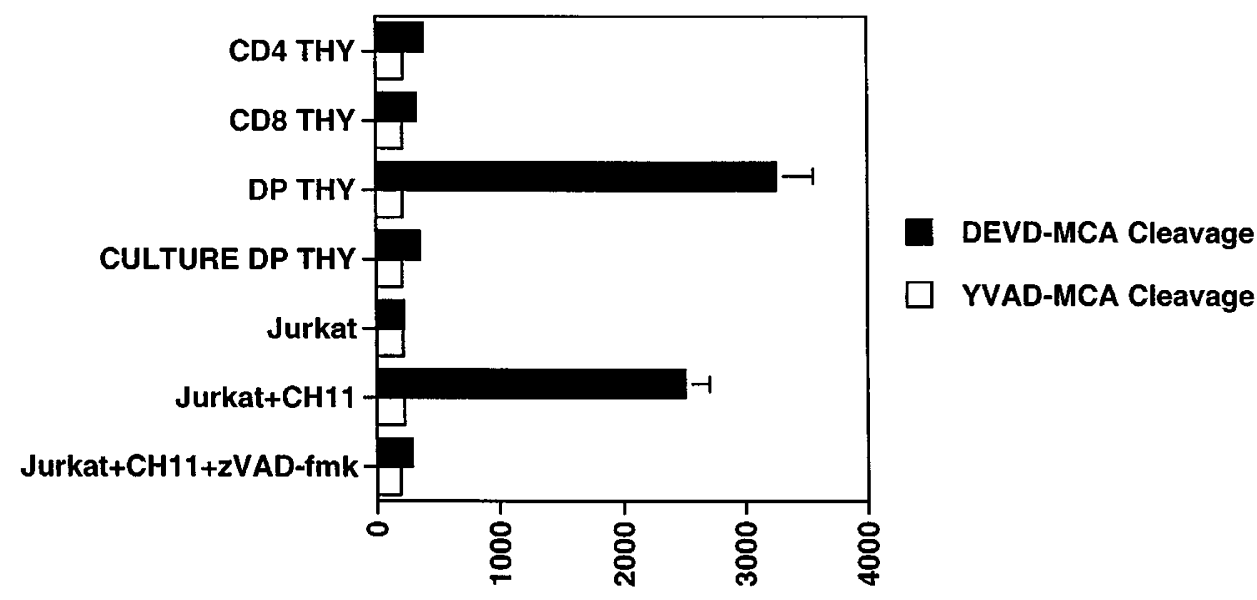

Caspase Activity (units)

Figure 1 Caspase activity in different thymocyte subpopulations. Freshly isolated thymocytes from young adult female C57BL/6 mice were fractionated by panning or magnetic bead separation to obtain DP thymocytes (DP THY), CD4 ${ }^{+}$(CD4 THY) and CD8 ${ }^{+}$(CD8 THY) SP thymocytes. CULTURE DP THY was obtained by culturing DP thymocytes for $12 \mathrm{~h}$ at $37^{\circ} \mathrm{C}$ in RPMI medium in the absence of any TCR stimulation. Cytosolic extracts were obtained from different populations and $10 \mu \mathrm{g}$ protein was used to measure the caspase-3-like activity and the caspase-1-like activity using DEVD-MCA (solid bar) and YVAD-MCA (empty bar), respectively. The enzymatic reaction was allowed to proceed for $8 \mathrm{~h}$ before reading. One unit corresponds to $0.8 \mathrm{pmole}$ of free amino-methyl-coumarin (AMC) in a $200 \mu \mathrm{l}$ reaction. As controls, $10 \mu \mathrm{g}$ of cytosolic extract from untreated (Jurkat), $500 \mathrm{ng} / \mathrm{ml}$ anti-CD95 antibody (CH11) treated (Jurkat+CH11), anti-CD95 antibody and $100 \mu \mathrm{M}$ zVAD-fmk co-treated (Jurkat+CH11+zVAD-fmk) Jurkat cells were also assayed for caspase activities. The absence of error bars in some columns is due to the fact that error values are too small to appear in the graph given the scale used. Each treatment was done in triplicates. This experiment was repeated three times and all results are in agreement to the data presented in the Figure 
A

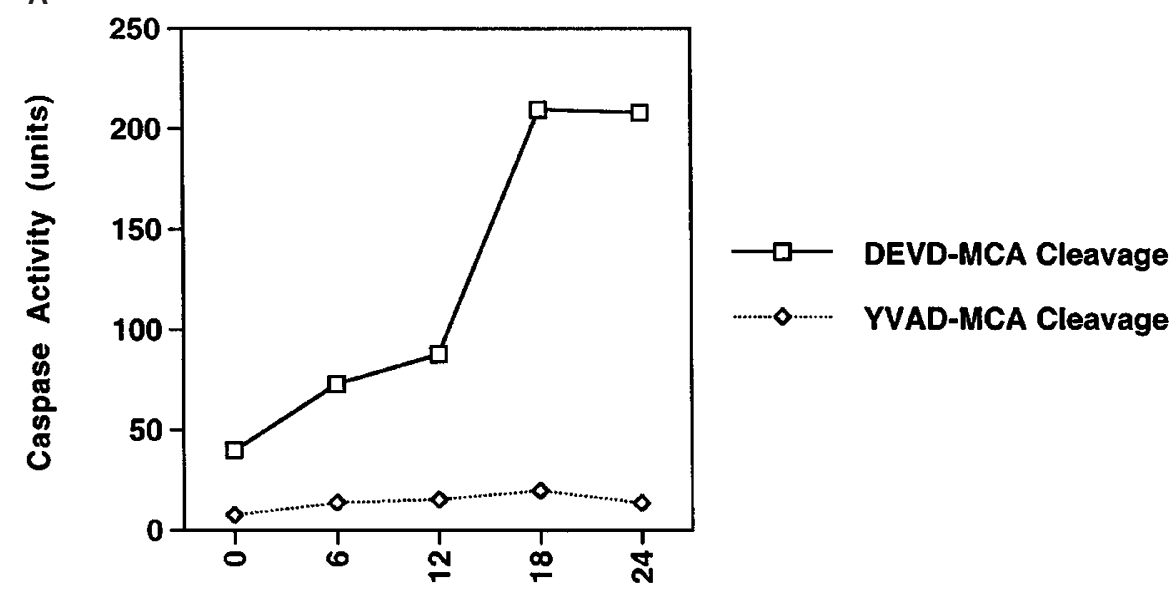

Hours

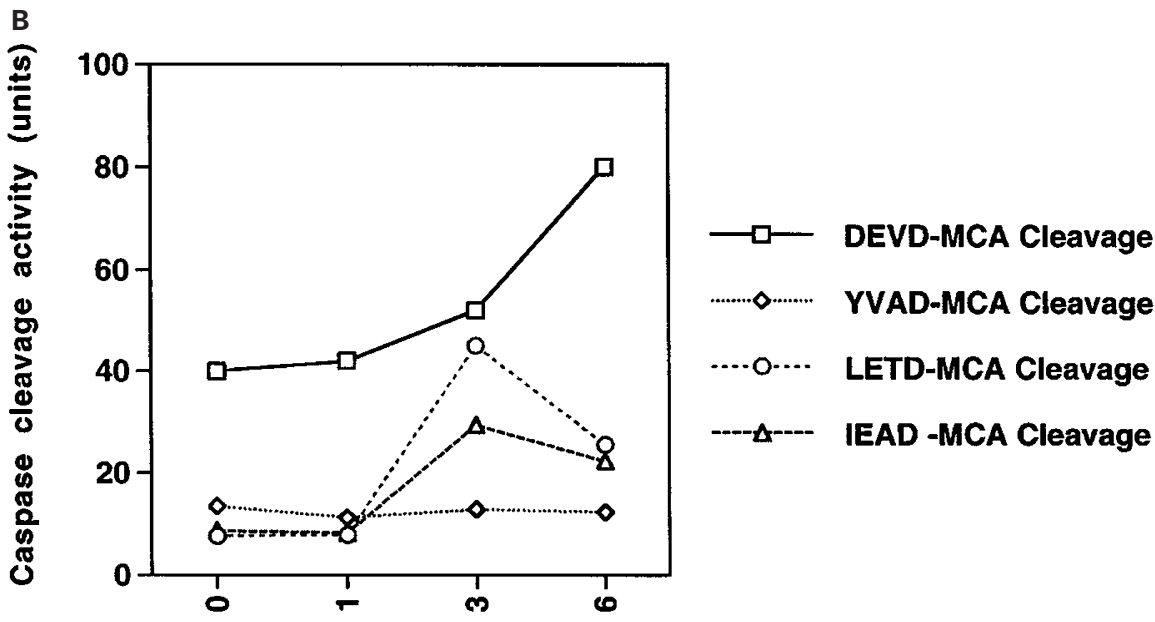

Hours

Figure 2 Caspase activities in DP thymocytes upon TCR/CD3-crosslinking in vitro. DP thymocytes were subjected to plate-bound anti-CD3 and anti-CD28 for 0 $24 \mathrm{~h}(\mathbf{A})$ or $0-6 \mathrm{~h}(\mathrm{~B})$ and were used to generate cytosolic extracts. Ten $\mu \mathrm{g}$ of each sample was assayed for caspase activities using either DEVD-MCA (square), YVAD-MCA (diamond), LETD-MCA (circle) and IEAD-MCA (triangle) as substrates. The enzymatic reaction was allowed to proceed for 30 min. One unit corresponds to 0.8 pmole of free AMC in a $200 \mu \mathrm{l}$ reaction. The absence of error bars in some columns is due to the fact that error values are too small to appear in the graph given the scale used. Each treatment was done in triplicates. This experiment was repeated three times and all results are in agreement to the data presented in the Figure

after the treatment, coincident with the initial increase of DEVD activity (Figure 2B). Hence, there is a substratespecificity and temporal order to caspase activation by antigen receptor crosslinking in thymocytes.

\section{Protease inhibitors specific for caspase-3 and caspase-8 subfamily proteases can block TCR-induced thymocyte death}

To directly assess the importance of caspases in TCRmediated thymocyte apoptosis, we employed several peptide protease inhibitors. zVAD-fmk inhibits various types of cell death, including mature T-lymphocyte apoptosis triggered by CD95-crosslinking, ${ }^{11}$ cell death induced by growth factor deprivation ${ }^{12}$ or cell cycle inhibition, ${ }^{11}$ and thymocyte apoptosis caused by pharmacological reagents ${ }^{20}$ and anti-CD3 or antigen treatments. ${ }^{14}$ The broad range of its inhibitory activity suggests the possibility that it blocks multiple caspases involved in cell death. In contrast to zVAD-fmk, YVAD-CHO has been suggested to specifically inactivate caspase-1 subfamily caspases. ${ }^{11}$ When DP thymocytes were treated for $24 \mathrm{~h}$ with TCR and CD28 stimulation, the percentage of live cells decreased from 80 to $20 \%$ (Figure 3 ). In the presence of $100 \mu \mathrm{M}$ zVAD-fmk, DP cell death was blocked completely. The caspase-3 subfamily inhibitor DEVD-fmk and caspase-8 specific inhibitor IETD-fmk also substantially inhibited the cell death, while YVAD-CHO did not block death even when $300 \mu \mathrm{M}$ of the inhibitor was used. zFAfmk, a negative control which lacks aspartate required for 
binding to caspases, had no effect on thymocyte cell death. We also tested total thymocytes from mice deficient for both $\mathrm{MHC}$ class I and class II $\left(\mathrm{MHC} \mathrm{I/I \textrm {I } ^ { - / }}\right)$ in these experiments. In $\mathrm{MHC} \mathrm{I} / \mathrm{II}^{-1-}$ mice, T-cell development is blocked at the DP stage due to the lack of MHC molecules to mediate thymic selection. ${ }^{21}$ More than $95 \%$ of thymocytes are $\mathrm{CD}^{+} \mathrm{CD}^{+}$double positive and no SP thymocytes develop. In this system, any possible interactions between SP and DP thymocytes and their consequent effects on DP thymocyte apoptosis are eliminated. Total thymocytes from these mice can be induced to undergo apoptosis upon CD3 and CD28-crosslinking in vitro. This death was efficiently inhibited by zVAD-fmk and effectively blocked by DEVD-fmk but not by YVAD-CHO (data not shown). Our data strongly support a role for caspase-3 and caspase-8 subfamily proteases in TCRmediated thymocyte apoptosis in vitro. In contrast to previous reports, ${ }^{11}$ caspase- 1 subfamily activity is not a prerequisite for the activation of other caspases and may not be required for this specific death pathway.

Additional experiments to verify these conclusions were directed at the role of caspases in thymocyte apoptosis that occurs in the thymic environment. Crosslinking CD3 alone can induce thymocytes to die in fetal thymic organ culture (FTOC). ${ }^{22}$ DP thymocytes are preferentially killed while SP thymocytes and $\mathrm{CD}^{-}{ }^{-} \mathrm{CD} 8^{-}$double negative (DN) thymocytes are spared. The dramatic decrease of DP thymocytes in culture following anti-CD3 treatment was very effectively inhibited by zVAD-fmk (Table 1). In contrast, YVAD-CHO, even up to $300 \mu \mathrm{M}$, could not

\section{Anti- Anti- Caspase CD3 CD28 Inhibitor}

$\%$ of live cells

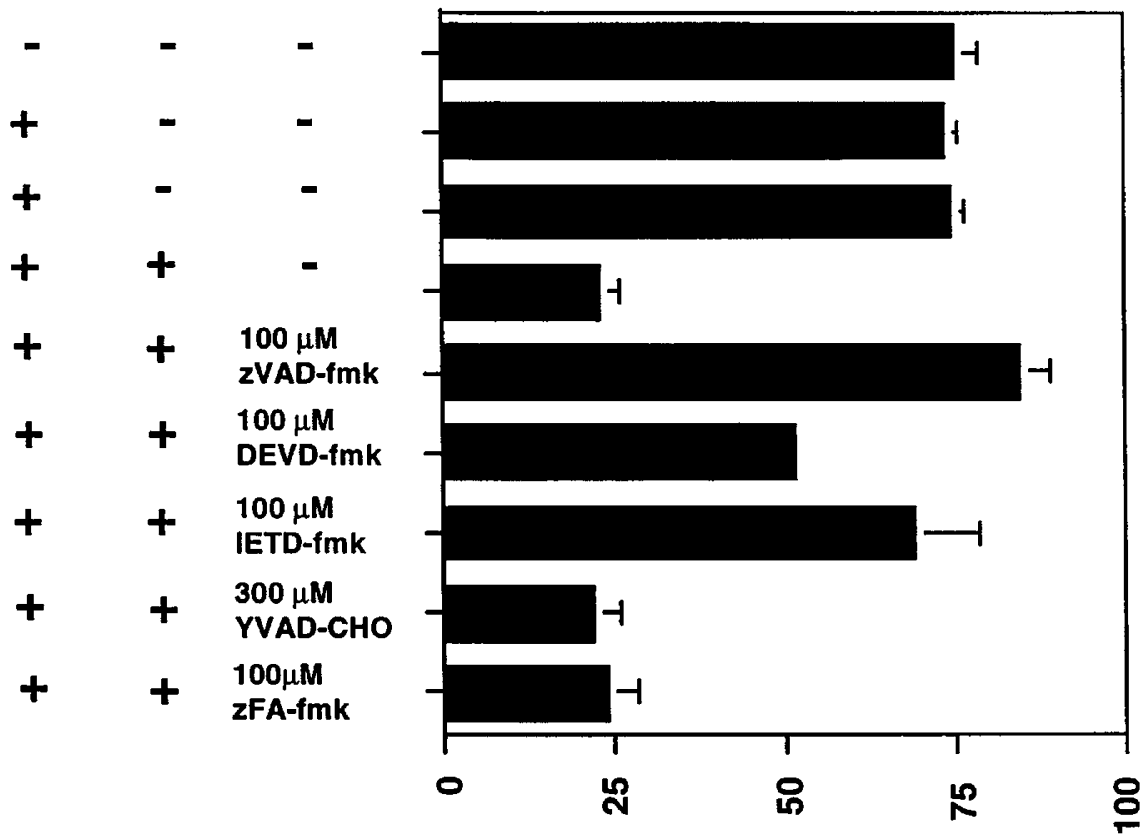

Figure 3 Inhibition of TCR/CD3-induced DP thymocyte apoptosis. DP thymocytes were treated with $10 \mu \mathrm{g} / \mathrm{ml}$ plate-bound anti-CD3 and/or $50 \mu \mathrm{g} / \mathrm{ml}$ anti-CD28 antibodies for $24 \mathrm{~h}$ in the presence or absence of different protease inhibitors. At the end of treatment thymocytes were stained with (propidium iodide) PI and subjected to flow cytometry to determine the cell viability. The absence of error bars in some columns is due to the fact that error values are too small to appear in the graph given the scale used. Each treatment was done in triplicates. This experiment was repeated three times and all results are in agreement to the data presented in the Figure

Table 1 Caspase inhibitors effectively block anti-CD3 antibody-induced DP thymocyte apoptosis in FTOC

\begin{tabular}{|c|c|c|c|c|c|c|c|c|}
\hline & \multicolumn{2}{|c|}{$\mathrm{CD}^{+} \mathrm{CD}^{+}$} & \multicolumn{2}{|c|}{$\mathrm{CD4}^{+} \mathrm{CD8}^{-}$} & \multicolumn{2}{|c|}{$\mathrm{CD4}^{-} \mathrm{CD8}^{+}$} & \multicolumn{2}{|c|}{$\mathrm{CD4}^{-} \mathrm{Cl}$} \\
\hline & Yield & $\%$ & Yield & $\%$ & Yield & $\%$ & Yield & $\%$ \\
\hline & 84664 & 75.69 & 5536 & 4.95 & 8576 & 7.66 & 13094 & 11.71 \\
\hline & 23964 & 44.54 & 4626 & 8.60 & 8970 & 16.67 & 16240 & 30.18 \\
\hline$+z V A D-f m k$ & 70662 & 80.36 & 7368 & 8.38 & 3074 & 3.50 & 6828 & 7.77 \\
\hline +YVAD-CHO & 31112 & 43.36 & 6402 & 8.92 & 9134 & 12.73 & 25107 & 34.99 \\
\hline$+\mathrm{ZFA}-\mathrm{fmk}$ & 33192 & 56.73 & 13440 & 22.97 & 2446 & 4.18 & 9430 & 16.12 \\
\hline
\end{tabular}

Ten d15 fetal thymic lobes were cultured in $24 \mathrm{~mm}$ polycarbonate transwell culture plates for 5 days to allow the development of DP thymocytes. Twenty $\mu \mathrm{g} / \mathrm{ml}$ of anti$\mathrm{CD} 3$ was then added to the medium with or without $100 \mu \mathrm{M}$ zVAD-fmk, $100 \mu \mathrm{M}$ zFA-fmk or $300 \mu \mathrm{M}$ YVAD-CHO. After $18 \mathrm{~h}$ antibody treatment, ten lobes were pooled together and live thymocytes were evaluated for the CD4 and CD8 expression by flow cytometry. This is a representative of four independent experiments 
protect DP thymocytes. Thus, within the thymic microenvironment, DP thymocytes can be protected from apoptosis by caspase- 3 inhibitors, but caspase- 1 inhibitors have no effect. In FTOC experiments, we also observed some effects of protease inhibitors on SP and DN populations, in both absolute cell number and percentage. These effects are not reproducible, and may represent experimental variations. The fact that zFA-fmk, which does not contain the aspartate required to bind to caspases and can not block caspase activity, also exhibits some effects on these populations, indicates that what we observed may not be specific to the inhibition of caspases.

An early event of apoptosis is the loss of plasma membrane asymmetry and the subsequent exposure of phosphotidylserine (PS) at the cell surface, which can be detected by fluorescently labeled Annexin $V^{23}$ Early apoptotic cells maintain membrane integrity as indicated by the exclusion of propidium iodide (PI) but are Annexin $\mathrm{V}$ positive. Double staining of cells with both Annexin VFITC and PI allows us to follow the progression of cell death. In the early stage of apoptosis, cells are Annexin $\mathrm{V}$ positive but $\mathrm{PI}$ negative. As early as $5 \mathrm{~h}$ after anti-
CD3 and anti-CD28 treatment, a population of Annexin V positive and $\mathrm{PI}$ negative thymocytes emerge $(9.7 \%$, Figure 4B). PS display was efficiently blocked by protease inhibitor zVAD-fmk (4.3\%, Figure 4C). A later event unique to the DP thymocyte apoptosis is the downregulation of CD4 and CD8 co-receptors following TCR treatment (Figure 4E). ${ }^{24}$ Ten hours after anti-CD3 and anti-CD28 antibody treatment, most DP thymocytes from $\mathrm{MHC} \mathrm{I} / \mathrm{II}^{-/-}$downregulated CD4 and CD8 coreceptors dramatically, however this event could not be blocked by zVAD-fmk (Figure 4F). Moreover, we found that these CD4/CD8 dull cells survived when anti-CD3 and anti-CD28 antibodies were removed and actually regained their CD4 and CD8 expression levels comparable to the control after $36 \mathrm{~h}$ of in vitro culture (Figure $4 G$ ). Similar cell numbers were recovered from the CD4/ CD8 re-expressed DP thymocyte sample and DP cells that had been induced to apoptosis (Figure $4 \mathrm{~F}$ and $\mathrm{G}$ ), in contrast to the $75 \%$ reduction of DP cells after a $24 \mathrm{~h}$ anti-TCR treatment (see Figure 3). Hence, PS display and $\mathrm{PI}$ incorporation, but not co-receptor downregulation, are reliable indicators of TCR-triggered commitment to apoptosis through caspase activation.
A

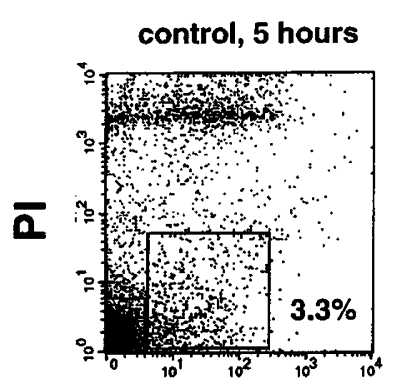

control, 10 hours

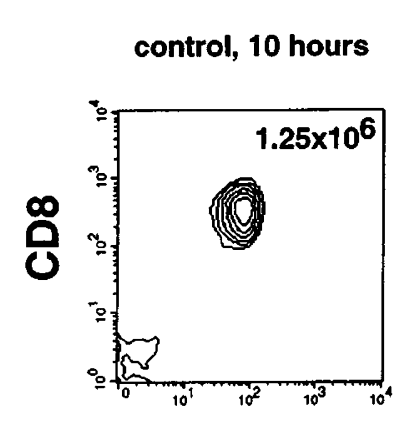

B

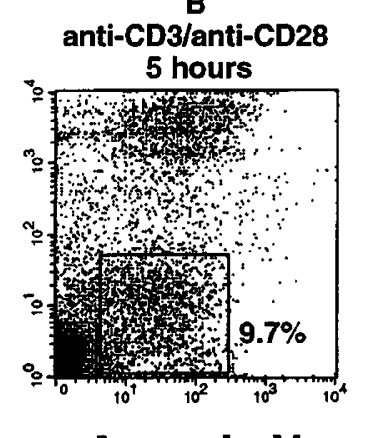

Annexin V
$\mathbf{E}$

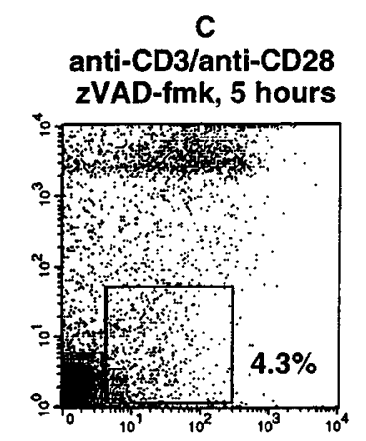

$\mathbf{F}$
G
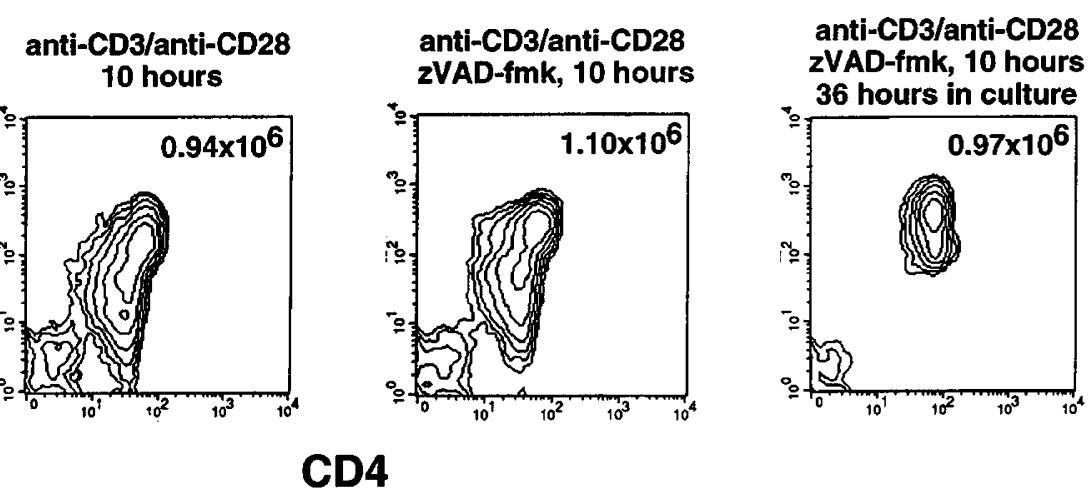

Figure 4 Caspase inhibitor blocks PS exposure but not the downregulation of CD4 and CD8 co-receptors. DP thymocytes from MHC I/II ${ }^{-/-}$were treated with $10 \mu \mathrm{g} / \mathrm{ml}$ plate-bound anti-CD3 and $50 \mu \mathrm{g} / \mathrm{ml}$ plate-bound anti-CD28 antibodies for $5 \mathrm{~h}$ in the presence or absence of $100 \mu \mathrm{M}$ of $\mathrm{zVAD}$-fmk then stained with Annexin V-FITC and PI (A-C). Alternatively, cells were treated with antibodies for $10 \mathrm{~h}$ then stained with anti-CD4-FITC and anti-CD8-PE antibodies before being subjected to flow cytometry analysis (D-F). Anti-CD3/anti-CD28 antibody-treated DP cells were also washed and cultured for an additional $36 \mathrm{~h}$ without antibodies in the presence of $100 \mu \mathrm{M}$ of zVAD-fmk, before staining with anti-CD4-FITC and anti-CD8-PE antibodies (G). Similar numbers of cells were recovered from this wash procedure and the control (no antibody) treatment (D). The numbers in $\mathbf{D}-\mathbf{G}$ indicate the live DP thymocyte yield per culture. Note that the strongly positive cells in $\mathbf{A}-\mathbf{C}$ are in the late stages of apoptosis or secondary necrosis 


\section{TCR stimulation-induced thymocyte apoptosis is normal in caspase-1 deficient mice}

To conclusively assess caspase-1 as a mediator for TCRinduced thymocyte apoptosis, we performed apoptosis assays with thymocytes from caspase- $1^{-1-}$ mice. ${ }^{25}$ Thymocytes from these mice were shown to be sensitive to dexamethasone and $\gamma$-radiation-induced apoptosis, while CD95-mediated cell death is impaired. ${ }^{17}$ The overall thymic development is intact. ${ }^{17,25}$ We subjected caspase- $1^{-/-}$thymocytes to CD3 and CD28 stimulation-induced apoptosis, which mimics the negative selection. We found no significant difference in cell loss between wildtype and mutant DP thymocytes (Figure 5A). As a control we also compared anti-CD95 antibody-induced thymocyte apoptosis in wildtype and caspase $-1^{-/-}$mice. We found no reproducible differences between wildtype and mutant mice using different doses of soluble anti-CD95 antibody in treatment (Figure 5B).
We also investigated the role of caspase- 1 in activationinduced mature T-cell death, using Concanavalin A (Con A)-stimulated T-cell blasts (CABs) from caspase-1 $1^{-1-}$ mice. Caspase-1 ${ }^{-1-} \mathrm{CAB}$ died readily when subjected to plate-bound anti-CD3 antibody (Figure $5 \mathrm{C}$ ). We observed no detectable differences in the percentage of cell death between caspase-1-1- and wildtype T-cells. Death of caspase- $1^{-1-}$ T-cells was efficiently inhibited by ZVAD$\mathrm{CHO}$, but not by YVAD-CHO. Hence, in contrast to previous reports, ${ }^{11}$ there is no demonstrable role for caspase-1 in anti-TCR mediated death in developing or mature $\mathrm{T}$-cells that are derived from normal animals.

\section{Discussion}

The involvement of caspases in TCR-induced thymocyte apoptosis was studied by examining the protease activity in DP thymocytes directly ex vivo. We found that DP thymocytes

A

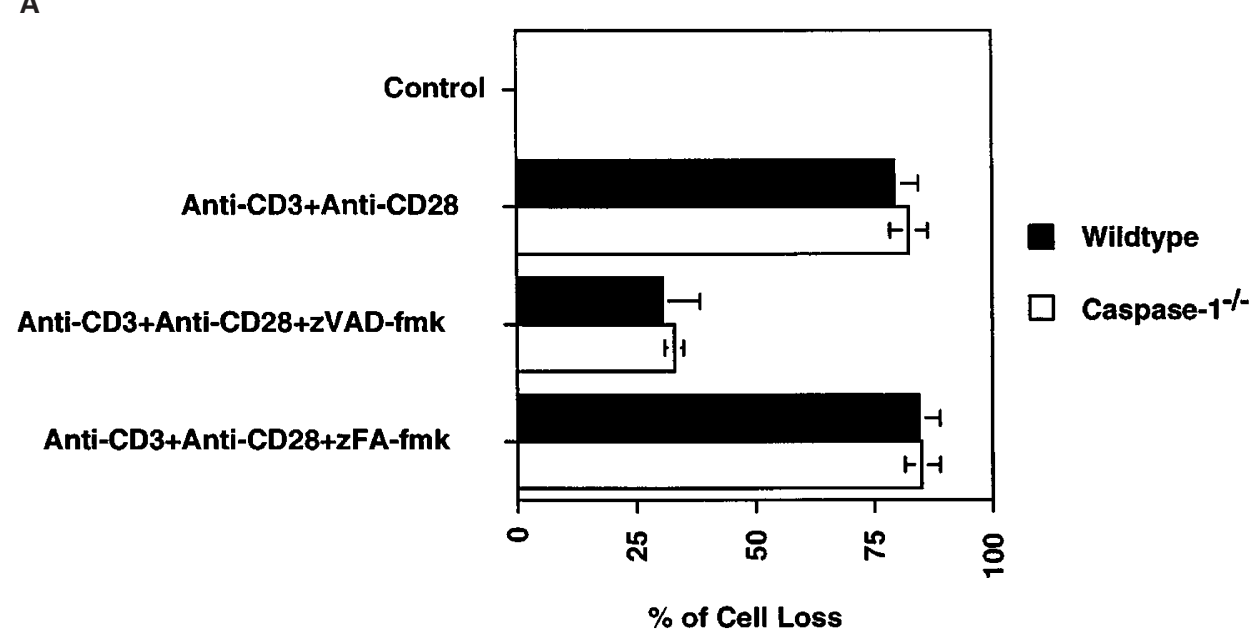

B

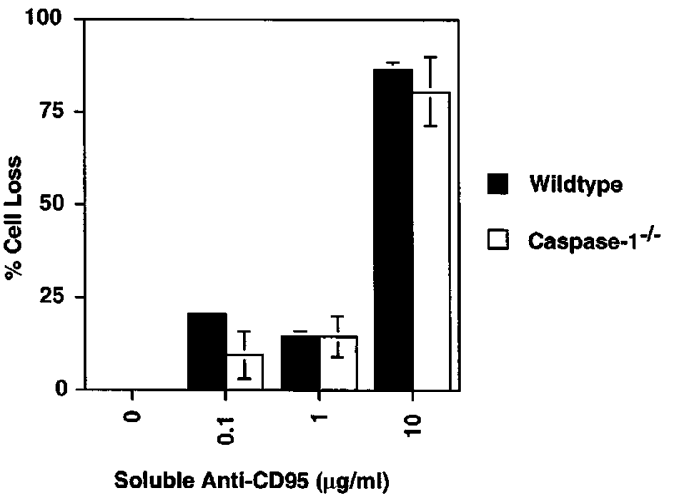

C

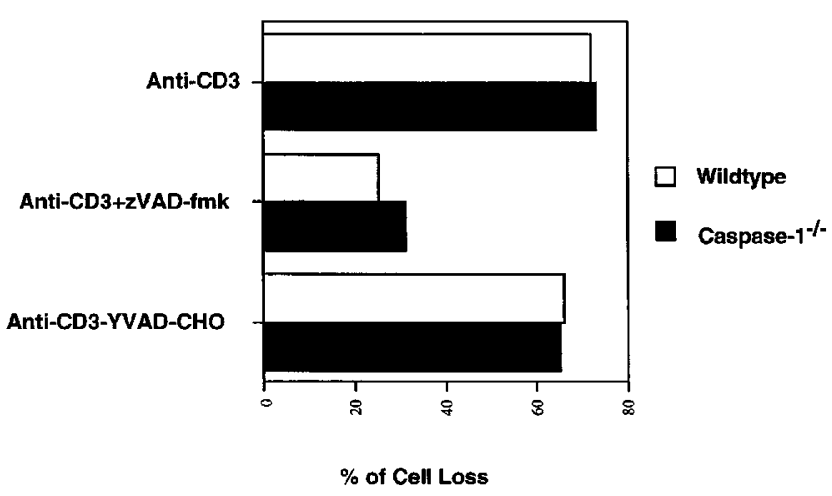

Figure 5 CD3- and CD95-crosslinking induce quantitatively equivalent apoptosis in either wildtype or caspase-1 ${ }^{-/-}$DP thymocytes and mature T-cell CABs. (A) Total thymocytes from wildtype (solid bars) and caspase $-1^{-1-}$ (empty bars) mice were treated with $10 \mu \mathrm{g} / \mathrm{ml}$ plate-bound anti-CD3 and $50 \mu \mathrm{g} / \mathrm{ml}$ anti-CD28 antibodies for $24 \mathrm{~h}$ in the presence or absence of $100 \mu \mathrm{M}$ zVAD-fmk or $100 \mu \mathrm{M}$ zFA-fmk as control. (B) Total thymocytes from wildtype (solid bars) and caspase $-1^{-1-}$ (empty bars) mice were treated with different concentrations of soluble anti-CD95 antibody (Jo2) for $18 \mathrm{~h}$. At the end of both treatments, thymocytes were stained with CD4-FITC and CD8-PE antibodies to identify the DP population and PI to determine the cell viability. (C) CABs from wildtype (solid bars) and caspase $-1^{-1-}$ (empty bars) mice were treated with $1 \mu \mathrm{g} / \mathrm{ml}$ of plate-bound anti-CD3 antibody in the absence or the presence of $100 \mu \mathrm{M}$ zVAD-fmk or $300 \mu \mathrm{M} \mathrm{YVAD-}$ $\mathrm{CHO}$ for $24 \mathrm{~h}$. Cell viability was determined by forward scatter and PI staining profiles using a flow cytometer. The percentage cell loss was calculated according to the following formula: \% cell loss $=1$ - (the number of viable cells underwent treatment/the number of viable cells untreated) $\times 100 \%$ 
possess large amounts of caspase-3 subfamily activity. CD4 and CD8 SP populations, as well as DN thymocyte population (data not shown), do not contain any protease activity above background. These results correlate with the maturational status associated with these various thymocyte populations. Since caspases are believed to be the principal biochemical pathway of apoptosis, our results are consistent with the concept that DP thymocytes are at the developmental stage where thymic selection events involving apoptosis is thought to take place. They are sensitive to TCR engagement and susceptible to TCR-mediated apoptosis. Contrasting with DP thymocytes, SP thymocytes are resistant to TCR-induced cell death and we find very little caspase activity in SP thymocytes. They have successfully passed thymic selection, and represent a more advanced developmental stage. ${ }^{26}$ We noticed that DP thymocytes after a $12 \mathrm{~h}$ in vitro culture contain little DEVD cleavage activity and postulated that the activity detected in fresh thymocytes may come from only a fraction of the DP thymocyte pool ex vivo. This fraction of cells may have received a negative selective signal in vivo and they undergo apoptosis during the in vitro culture. The remaining DP thymocytes may contain the DP cells that have not received negative selection signal or the DP cells that have passed negative selection and become TCR ${ }^{\text {high }}$ cells. $^{27,28} \mathrm{DP}$ culture in the presence of zVAD-fmk always yielded more DP thymocytes than control without the inhibitor (data not shown), presumably resulting from rescuing this fraction of negatively selected thymocytes.

Our results also demonstrated a selective activation of caspases in DP thymocytes: the caspase-3 subfamily is active in this thymocyte population, while the caspase-1 subfamily is inactive. These data are reinforced by in vitro experimental results showing that caspase-3-like activity is strongly activated in response to anti-CD3 and anti-CD28 treatment, which leads to apoptosis. Furthermore, DEVD-fmk but not YVAD-CHO can inhibit death. Finally, DP thymocytes from caspase-1 $1^{-1-}$ mice remain fully sensitive to TCRinduced apoptosis. Previous results have suggested a role for caspase-1 in apoptosis based on the induction of death by overexpression, the prevention of apoptosis by a caspase-1 specific inhibitor and the resistance to CD95-mediated apoptosis in caspase-1 $1^{-1-}$ mice. Apoptosis from transfection of caspase-1 may result from overloading the system with the active enzyme so that its specificity is compromised. YVAD-CHO, a tetrapeptide caspase-1 inhibitor based on the cleavage site in prolL- $1 \beta{ }^{11}$ was shown to inhibit CD95mediated apoptosis by blocking the activation of caspase-3like activity in W4 cell line. ${ }^{29}$ It was therefore proposed that in CD95-mediated apoptosis caspase- 1 and caspase-3 are sequentially activated to transduce and execute the death program. However, in our experiments, caspase-1-like activity does not precede caspase-3-like activity nor does caspase-1 appear required in TCR-induced thymocyte apoptosis. Based on these results, we conclude that caspase-1 is not a prerequisite for TCR engagementinduced thymocyte apoptosis. As a control, and in contrast to the previous results, ${ }^{16}$ we also studied CD95-induced thymocyte apoptosis in caspase- $1^{-/-}$thymocytes and found no detectable differences. Our data support certain groups' results ${ }^{25,29}$ suggesting that caspase-1 does not participate in
CD95-mediated thymocyte cell death and disagree with the results of others suggesting a role for caspase- 1 in thymocyte apoptosis. ${ }^{17}$ It is conceivable that different results might relate to different genetic backgrounds of the caspase-1 $1^{-1-}$ mice, or other variables, but no evidence has yet been generated that indicates an essential role for caspase-1 activity in normal TCR-mediated thymocyte apoptosis. The primary function of caspase-1 may not be apoptosis, from our results and the others', but processing prolL-1 $\beta$. The mild effects of caspase-1 on apoptosis could be related to secondary effects due to IL-1 $\beta$. Friedlander et al. ${ }^{30}$ have reported that either IL-1 receptor antagonist or YVAD-CHO alone can inhibit apoptosis by inhibiting IL-1 $\beta$ activity in motorneurons following neurotrophic factor deprivation. Hence, the experiments showing decreased apoptosis in thymocytes could be attributable to an IL-1 $\beta$ effect.

Previous results have showed that CD95-mediated mature T-cell death is normal in caspase- $1^{-1-}$ mice. ${ }^{29}$ Recent data suggest that antigen-induced T-cell death can be mediated by other death receptors. ${ }^{31}$ We investigated the role of caspase-1 in apoptosis of activated T-cells induced by TCR re-stimulation, and observed no detectable difference between wildtype and caspase- $1^{-1-}$ T-cells. We conclude that caspase-1 is not required for TCR-induced mature T-cell apoptosis. In this respect, the TCR-triggered death pathways appear analogous in mature and developing T-cells.

The caspase-3-like activity we observed in DP thymocytes ex vivo and in vitro supports the hypothesis that caspase-3 subfamily is involved in thymocyte apoptosis. However, thymocytes deficient for caspase-3 remain sensitive to TCR-induced apoptosis. ${ }^{15}$ We speculate that other members of caspase-3 subfamily, such as caspase-7 and caspase-6, which share the same D-X-X-D motif in the substrates, may account for the DEVD cleavage activity we observed. This could explain our result showing that DEVDfmk, that is able to block all caspase-3-like proteases, could inhibit DP thymocyte death.

In addition to the caspase-3-like activity, transient activities of caspase- 8 and caspase-10 were also present in the early phase of DP thymocyte apoptosis when caspase3 activity began to rise and cells started to become Annexin V positive. IETD-fmk, an inhibitor specific for caspase-8, blocked DP thymocyte death very effectively. These data are reminiscent to the recent results obtained from mature $T$ cell apoptosis studies. ${ }^{32,33}$ CD95-mediated mature T-cell apoptosis requires a recruitment of cellular proteins, including caspase-8 and possibly caspase-10, to the cytoplasmic portion of CD95 through the death domain (DD) containing molecule, such as FADD. ${ }^{34}$ Upon binding to the CD95/FADD complex, caspase- 8 is thereby processed and activated. An active caspase-8 can then activate its downstream caspases. At least in CD95-induced mature T-cell apoptosis, caspase-8 is the first and indispensable caspase activated in the apoptosis pathway. Our studies extend this notion into thymocyte apoptosis. The early onset of caspase-8 activity and effective blockade of cell death by IETD-fmk indicates that caspase- 8 activation is one of the earliest events of apoptosis and is important for initiating cell death in DP thymocytes. 
Another interesting observation in our study is that the downregulation of CD4/CD8 co-receptors on DP thymocytes was not associated with the death pathway. At a dose sufficient to block the exposure of phosphotidylserine and apoptosis, zVAD-fmk could not inhibit the downregulation of co-receptors. In long-term culture (36 h) in the absence of apoptotic stimuli and in the presence of zVAD-fmk, the CD4/CD8 dull cells eventually regained high levels of co-receptor expression. We postulate that the downregulation of thymocyte co-receptors is not intrinsically associated with the death process. One possible scenario is that DP thymocytes would downregulate their co-receptors upon the TCR engagement. If the engagement is very strong, as in the case of negative selection, these thymocytes will be subjected to an irreversible apoptotic pathway. If this engagement is intermediate in intensity these CD4/CD8 dull thymocytes will upregulate one of the co-receptors and develop to the SP stage. ${ }^{35}$ Hence, we propose that apoptosis is a distinct pathway from co-receptor down-regulation during thymocyte development.

\section{Materials and Methods}

\section{Mice}

Six- to eight-week-old female C57BL/6 mice and day 15 timedpregnant $\mathrm{NIH} /$ Swiss mice were obtained from the National Cancer Institute, Frederick Cancer Research and Development Center (Frederick, MD, USA). Young adult female mice deficient in both MHC class I and II expression (C57BL/6JAi-A $\beta^{\mathrm{b}}[\mathrm{KO}]-\beta 2 \mathrm{~m}[\mathrm{KO}]$, or $\mathrm{MHCl} / \mathrm{II}^{-1-}$ ) were obtained from Taconic Farms, Inc. (Germantown, NY, USA). Six- to eight-week-old female caspase $-1^{-I-}$ mice were obtained from BASF Bioresearch Corporation (Worcester, MA, USA).

\section{Antibodies and reagents}

Fluorescently-labeled antibodies specific for CD4 (RM4-5) and CD8 (53-6.7) and purified antibodies against CD3 (2C11), CD28 (37.51), and CD95 (Jo2) were obtained from PharMingen (San Diego, CA, USA). Anti-human CD95 antibody ( $\mathrm{CH} 11)$ was obtained from Kamiya (Tukwila, WA, USA). Protease inhibitors Cbz-Val-Ala-Asp-fluoromethyl ketone (zVAD-fmk), Cbz-Asp-Glu-Val-Asp-fluoromethyl ketone (DEVD-fmk), Cbz-lle-Glu-Thr-Asp-fluoromethyl ketone (IETDfmk), Cbz-Phe-Ala-fluoromethyl ketone (zFA-fmk) and protease substrates acetyl-Ile-Glu-Ala-Asp-4-methyl-coumary-7-amide (IEADMCA), Cbz-Leu-Glu-Thr-Asp-4-methyl-coumary-7-amide (LETD-MCA) were purchased from Enzyme Systems Products (Dublin, CA, USA), and dissolved according to the manufacturer's instruction. zFA-fmk is a derivatized peptide analogous to ZVAD but lacking the aspartate required for binding to caspases and was used as a negative control in our experiments. The caspase- 1 subfamily inhibitor acetyl-Tyr-ValAla-Asp-CHO (YVAD-CHO), protease substrates acetyl-Tyr-Val-AlaAsp 4-methyl-coumary-7-amide (YVAD-MCA) and acetyl-Asp-Glu-ValAsp 4-methyl-coumary-7-amide (DEVD-MCA) were purchased from Peptide International (Louisville, KY, USA). Annexin V staining reagents were obtained from Trevigen (Gaithersburg, MD, USA). Concanavalin A and $\alpha$-methyl mannoside were obtained from Sigma (St. Louis, MO, USA).

\section{Isolation of DP thymocytes and apoptosis assay}

The thymocyte isolation procedures followed in our studies were described previously. ${ }^{19}$ Briefly, DP thymocytes were purified from young adult female C57BL/6 mice by panning on anti-CD8 coated plates. $\mathrm{CD}^{+}$and $\mathrm{CD} 8^{+} \mathrm{SP}$ thymocytes were purified by staining total thymocytes with either rat anti-mouse CD8 or rat anti-mouse CD4 antibodies, and incubating them with magnetic beads (Dynal International, Oslo, Norway) coated with sheep anti-rat antibodies to deplete CD8 positive or CD4 positive cells, respectively. In vitro killing assays using anti-CD3 and anti-CD28 antibodies were performed as previously published. ${ }^{19}$ In short, 24-well tissue culture plates were coated with $10 \mu \mathrm{g} / \mathrm{ml}$ anti-CD3 antibody and $50 \mu \mathrm{g} / \mathrm{ml}$ anti-CD28 antibody in PBS overnight. Purified DP thymocytes or total thymocytes $\left(2.5 \times 10^{6}\right)$ were cultured in the antibody-coated plate in $0.5 \mathrm{ml}$ of RPMI medium supplemented with 10\% FCS and antibiotics for 18 or $24 \mathrm{~h}$. At the end of the culture, thymocytes were harvested, stained and subjected to flow cytometry. Annexin $\mathrm{V}$ staining was performed following the manufacturer's instruction. Protease inhibitors were added at the beginning of the culture at concentrations indicated in the figures. To study co-receptor expression, we TCR-stimulated DP thymocytes in the presence of protease inhibitor for $10 \mathrm{~h}$, then washed the cells and cultured them in the presence of protease inhibitor and the absence of anti-CD3 and anti-CD28 antibodies for additional $36 \mathrm{~h}$. We also used soluble anti-CD95 (Jo2) antibody at various concentrations (as described in Figure $5 \mathrm{~B}$ ) in thymocyte cultures for $18 \mathrm{~h}$ to induce apoptosis.

\section{TCR-mediated mature T-cell death assay}

BALB/c mouse lymph node cells were stimulated with $5 \mu \mathrm{g} / \mathrm{ml}$ Con A for $48 \mathrm{~h}$, washed with $10 \mathrm{mg} / \mathrm{ml}$ of $\alpha$-methyl mannoside and then incubated in EHAA complete medium supplemented with $10 \mathrm{IU} / \mathrm{ml}$ of interleukin-2 for $48 \mathrm{~h}$. Viable T-lymphocyte CABs were purified by density gradient centrifugation and resuspended in fresh EHAA complete medium supplied with the same amount of IL-2. Fifty thousand T-cells were seeded into each well of 96-well plates precoated with $1 \mu \mathrm{g} / \mathrm{ml}$ of anti-CD3 (2C11) and incubated for $24 \mathrm{~h}$. Quantitation of viable cell recovery was carried out by a flow cytometric analysis detailed previously. ${ }^{31}$ Briefly, four wells of cells were pooled and stained with $10 \mathrm{ul}$ of $100 \mu \mathrm{g} / \mathrm{ml}$ propidium iodide. Samples were collected on the FACScan II (Becton Dickinson, Franklin Lakes, NJ, USA) flow cytometer for $30 \mathrm{~s}$ constant time. The viable cell recovery was next determined by forward scatter profile and propidium iodide exclusion.

\section{Protease assay}

One million thymocytes were washed with PBS once and then with cytosol extract buffer (CEB, $50 \mathrm{mM}$ PIPES, pH 7.4, $50 \mathrm{mM} \mathrm{KCl,} 5 \mathrm{mM}$ EGTA, $2 \mathrm{mM} \mathrm{MgCl}_{2}$, $1 \mathrm{mM}$ DTT, $10 \mu \mathrm{M}$ cytochalasin B, $1 \mathrm{mM}$ PMSF, $0.5 \mathrm{mg} / \mathrm{ml}$ leupeptin and $3 \mu \mathrm{g} / \mathrm{ml}$ antipain), and resuspended in $50 \mathrm{ml}$ CEB. Cells were then subjected to three rounds of freezing and thawing (at $4^{\circ} \mathrm{C}$ ) and centrifuged. The protein concentration of the supernatant was determined with Bio-Rad Protein Assay reagents from Bio-Rad Laboratories (Hercules, CA, USA) following the manufacturer's protocol. Ten $\mu \mathrm{g}$ of protein was diluted in $200 \mathrm{ml}$ of thiol free-buffer (TFB, $10 \%$ sucrose, $30 \mathrm{mM}$ HEPES, $\mathrm{pH} 7.4,5 \mathrm{mM}$ DTT and $10 \mathrm{mM} \mathrm{CaCl}$ ) containing $25 \mu \mathrm{M}$ of either DEVD-MCA or YVAD-MCA. The proteolysis activity was evaluated at $30 \mathrm{~min}$ or $8 \mathrm{~h}$ using a FluoroStar spectrofluorometer from Tecam (Durham, NC, USA) set at an excitation wavelength of $390 \mathrm{~nm}$ and an emission wavelength of $460 \mathrm{~nm}$. 


\section{FTOC thymocyte killing assay}

Fetal thymic organs were harvested from $\mathrm{NIH} /$ Swiss mice at day 15 of gestation and cultured in $24 \mathrm{~mm}$ polycarbonate transwell culture plates from Costar (Cambridge, MA, USA). Ten lobes were cultured in one transwell situated in 6-well cluster plate containing $1.8 \mathrm{ml}$ EHAA medium supplemented by $10 \%$ FCS and antibiotics. The culture was maintained for 5 days with the medium replenished every other day. At the end of the 5-day culture the medium was replaced with fresh medium containing $20 \mu \mathrm{g} / \mathrm{ml}$ of anti-CD3 with or without protease inhibitors. At the end of the $18 \mathrm{~h}$ antibody treatment, thymocytes from ten lobes were harvested and pooled for the determination of cell yield by flow cytometry.

\section{Acknowledgements}

We thank Drs. Erastus C. Dudley, Richard M. Siegel, Juan Carlos ZúñigaPflücker for critically reading the manuscript, and Dr. Subhashis Banerjee for kindly providing caspase-1-1- mice to us. Di Jiang is in partial fulfilment of a Ph.D. dissertation from George Washington University, Washington. DC, USA.

\section{References}

1. Henkart PA (1996) ICE family proteases: mediators of all apoptotic cell death? Immunity 4: 195-201

2. Thornberry NA, Bull HG, Calaycay JR, Chapman KT, Howard AD, Kostura MJ, Miller DK, Molineaux SM, Weidner JR, Aunins J, Elliston KO, Ayala JM, Casano FJ, Chin J, Ding GJF, Egger LA, Gaffney EP, Limjuco G, Palyha OC, Raju SM, Rolando AM, Salley JP, Yamin TT, Lee TD, Shively JE, Maccross M, Mumford RA, Schmidt JA and Tocci MJ. (1992) A novel heterodimeric cysteine protease is required for interleukin-1 beta processing in monocytes. Nature 356: 768-774

3. Horvitz HR, Shaham S and Hengartner MO (1994) The genetics of programmed cell death in the nematode Caenorhabditis elegans. Cold Spring Harbor Symposia on Quantitative Biology 59: 377-385

4. Nicholson DW and Thornberry NA (1997) Caspases: killer proteases. Trends Biochem. Sci. 22: 299-306

5. Margolin N, Raybuck SA, Wilson KP, Chen W, Fox T, Gu Y and Livingston DJ (1997) Substrate and inhibitor specificity of interleukin-1 beta-converting enzyme and related caspases. J. Biol. Chem. 272: 7223-7228

6. Talanian RV, Quinlan C, Trautz S, Hackett MC, Mankovich JA, Banach D, Ghayur T, Brady KD and Wong WW (1997) Substrate specificities of caspase family proteases. J. Biol. Chem. 272: $9677-9682$

7. Thornberry NA, Rano TA, Peterson EP, Rasper DM, Timkey T, GarciaCalvo M, Houtzager VM, Nordstrom PA, Roy S, Vaillancourt JP, Chapman KT and Nicholson DW (1997) A combinatorial approach defines specificities of members of the caspase family and granzyme B. Functional relationships established for key mediators of apoptosis. J. Biol. Chem. 272: 17907-17911

8. Cain K, Inayat-Hussain SH, Couet C and Cohen GM (1996) A cleavage-sitedirected inhibitor of interleukin-1 beta-converting enzyme-like proteases inhibits apoptosis in primary cultures of rat hepatocytes. Biochem. J. 314: 27-32

9. Slee EA, Zhu H, Chow SC, MacFarlane M, Nicholson DW and Cohen GM (1996) Benzyloxycarbonyl-Val-Ala-Asp (OMe) fluoromethylketone (Z-VAD.FMK) inhibits apoptosis by blocking the processing of CPP32. Biochemical J. 315: 21-24

10. Enari M, Hug H and Nagata S (1995) Involvement of an ICE-like protease in Fasmediated apoptosis. Nature 375: 78-81

11. Enari M, Talanian RV, Wong WW and Nagata S (1996) Sequential activation of ICE-like and CPP32-like proteases during Fas-mediated apoptosis. Nature 380: $723-726$

12. Sarin A, Wu ML and Henkart PA (1996) Different interleukin-1 beta converting enzyme (ICE) family protease requirements for the apoptotic death of $\mathrm{T}$ lymphocytes triggered by diverse stimuli. J. Exp. Med. 184: $2445-2450$
13. Schlegel J, Peters I, Orrenius S, Miller DK, Thornberry NA, Yamin TT and Nicholson DW (1996) CPP32/apopain is a key interleukin-1 beta converting enzyme-like protease involved in Fas-mediated apoptosis. J. Biol. Chem. 271: $1841-1844$

14. Clayton LK, Ghendler Y, MizoguchiE, Patch RJ, Ocain TD, Orth K, Bhan AK, Dixit VM and Reinherz EL (1997) T-cell receptor ligation by peptide/MHC induces activation of a caspase in immature thymocytes: the molecular basis of negative selection. EMBO J. 16: 2282-2293

15. Alam A, Braun MY, Hartgers F, Lesage S, Cohen L, Hugo P, Denis F and Sekaly RP (1997) Specific activation of the cysteine protease CPP32 during the negative selection of $\mathrm{T}$ cells in thymus. J. Exp. Med. 186: $1503-1512$

16. Kuida K, Zheng TS, Na S, Kuan C, Yang D, Karasuyama H, Rakic P and Flavell RA (1996) Decreased apoptosis in the brain and premature lethality in CPP32deficient mice. Nature 384: 368-372

17. Kuida K, Lippke JA, Ku G, Harding MW, Livingston DJ, Su MS and Flavell RA (1995) Altered cytokine export and apoptosis in mice deficient in interleukin-1 beta converting enzyme. Science 267: 2000-2003

18. Surh CD and Sprent J (1994) T-cell apoptosis detected in situ during positive and negative selection in the thymus. Nature 372: 100-103

19. Punt JA, Osborne BA, Takahama Y, Sharrow SO and Singer A (1994) Negative selection of $\mathrm{CD} 4+\mathrm{CD} 8+$ thymocytes by $\mathrm{T}$ cell receptor-induced apoptosis requires a costimulatory signal that can be provided by CD28. J. Exp. Med. 179: $709-713$

20. Fearnhead HO, Dinsdale D and Cohen GM (1995) An interleukin-1 betaconverting enzyme-like protease is a common mediator of apoptosis in thymocytes. FEBS Lett. 375: 283-288

21. Grusby MJ, Auchincloss Jr., H, Lee R, Johnson RS, Spencer JP, Zijlstra M, Jaenisch R, Papaioannou VE and Glimcher LH (1993) Mice lacking major histocompatibility complex class I and class II molecules. Proc. Natl Acad. Sci. USA 90: 3913-3917

22. Smith CA, Williams GT, Kingston R, Jenkinson EJ and Owen JJT (1989) Antibodies to CD3/T-cell receptor complex induce death by apoptosis in immature T cells in thymic cultures. Nature 337: 181-184

23. van Engeland M, Ramaekers FC, Schutte B and Reutelingsperger CP (1996) A novel assay to measure loss of plasma membrane asymmetry during apoptosis of adherent cells in culture. Cytometry 24: 131-139

24. Swat $W$, Ignatowicz $L$, von Boehmer $H$ and Kisielow $P$ (1991) Clonal deletion of immature $\mathrm{CD} 4+8+$ thymocytes in suspension-culture by extrathymic antigenpresenting cells. Nature 351: 150-153

25. LiP, Allen H, Banerjee S, Franklin S, Herzog L, Johnston C, McDowell J, Paskind M, Rodman L, Salfeld J, Towne E, Tracey D, Wardwell S, Wei FY, Wong W, Kamen $R$ and Seshadri T. (1995) Mice deficient in IL-1 beta-converting enzyme are defective in production of mature $\mathrm{IL}-1$ beta and resistant to endotoxic shock. Cell 80: 401-411

26. von Boehmer H, Teh HS and Kisielow P (1989) The thymus selects the usefeul, neglects the useless, and destroys the harmful. Immunol. Today. 10: $57-61$

27. Ghendler Y, Hussey RE, Witte T, Mizoguchi E, Clayton LK, Bhan AK, Koyasu S, Chang HC, Reinherz EL (1997) Double-positive T cell receptor(high) thymocytes are resistant to peptide/major histocompatibility complex ligand-induced negative selection. Eur. J. Immunol. 27: 22792289

28. Ghendler Y, Mizoguchi E, Bhan AK, Clayton LK (1998) Double-positive thymocytes resistant to antigen-MHC-induced negative selection lack active caspase. Int. Immunol. 10: 767-774

29. Smith DJ, McGuire MJ, Tocci MJ and Thiele DL (1997) IL-1 beta convertase (ICE) does not play a requisite role in apoptosis induced in T lymphoblasts by Fasdependent or Fas-independent CTL effector mechanisms. J. Immunol. 158: $163-170$

30. Friedlander RM, Gagliardini V, Rotello RJ and Yuan J (1996) Functional role of interleukin 1 beta (IL-1 beta) in IL-1 beta-converting enzyme-mediated apoptosis. J. Exp. Med. 184: 717-724

31. Zheng L, Fisher G, Miller RE, Peschon J, Lynch DH and Lenardo MJ (1995) Induction of apoptosis in mature T cells by tumour necrosis factor. Nature 377 : 348-351

32. Boldin MP, Goncharov TM, Goltsev YV and Wallach D (1996) Involvement of $\mathrm{MACH}$, a novel MORT1/FADD-interacting protease, in Fas/APO-1- and TNF receptor-induced cell death. Cell 85: 803-815 
33. Muzio M, Chinnaiyan AM, Kischkel FC, O'Rourke K, Shevchenko A, Ni J, Scaffidi C, Bretz JD, Zhang M, Gentz R, Mann M, Krammer PH, Peter ME and Dixit VM (1996) FLICE, a novel FADD-homologous ICE/CED-3-like protease, is recruited to the CD95 (Fas/APO-1) death-inducing signaling complex. Cell 85: 817-827

34. Medema JP, Scaffidi C, Kischkel FC, Shevchenko A, Mann M, Krammer PH and Peter ME (1997) FLICE is activated by association with the CD95 death-inducing signaling complex (DISC). EMBO J. 16: 2794-2804
35. Lucas B and Germain RN (1996) Unexpectedly complex regulation of CD4/CD8 coreceptor expression supports a revised model for CD4+CD8+ thymocyte differentiation. Immunity 5: 461-477 